\title{
La democracia precaria. El sistema del sorteo de la democracia ateniense antigua en Francisco Rodríguez Adrados y Antonio Tovar Llorente*
}

\author{
Precarious Democracy. Sortition and Ancient Athenian Democracy \\ in Francisco Rodríguez Adrados and Antonio Tovar Llorente
}

JOSÉ LUIS BELLÓN AGUILERA**

\begin{abstract}
Resumen: El presente artículo explora dos obras pioneras en España sobre la Atenas democrática de la antigüedad, escritas durante el franquismo: Vida de Sócrates $\left(1947,1953^{2}\right.$, reed. 1966, 1984) y La democracia ateniense $\left(1975,1966^{1}\right.$ bajo el título Ilustración y política en la Grecia clásica), escritas respectivamente por Antonio Tovar Llorente (1911-1985) y Francisco Rodríguez Adrados (nacido 1922). El artículo discute, centrándose en el tratamiento en las obras del sorteo -el elemento más distintivo de la democracia antigua ateniense-, las contradicciones internas, las lecturas sesgadas ideológicamente, así como los logros. El análisis se basa, primero, en la oposición entre ciencia e ideología, partiendo de la lectura de Ellen M. Wood sobre estudiosos del mundo clásico y, segundo, en un marco de sociología de los intelectuales.

Palabras clave: Tovar, Adrados, franquismo, sorteo, democracia, ateniense, ideología, ciencia,
\end{abstract}

\begin{abstract}
This article explores two groundbreaking studies of Ancient Democratic Athens in Franco's Spain: Life of Socrates $\left(1947,1953^{2}\right.$, reed. 1966, 1984) and The Athenian Democracy (1975, $1966^{1}$, then entitled Enlightenment and Politics in Classical Greece), written, respectively, by renowned scholars Antonio Tovar Llorente (19111985) and Francisco Rodríguez Adrados (born 1922). The article analyses, through a discussion focused on the treatment in those works of the most distinctive element of Ancient Athenian Democracy, the selection by lot (sortition), their internal contradictions, ideological misreadings, as well as the achievements. Firstly, the analysis is based on the opposition between ideology and science, as read by Ellen M. Wood in classical scholars and, secondly, on a framework of Sociology of the intellectuals.
\end{abstract}

Keywords: Tovar, Adrados, francoism, sortition, athenian, democracy, ideology, science, sociology.

Fecha de recepción: 21/10/2016. Fecha de aceptación: 30/01/2017.

* El presente texto está realizado en el marco del proyecto de I+D: «La recepción de la filosofía grecorromana en la filosofía y las ciencias humanas en Francia y España desde 1980 hasta la actualidad» FFI2014-53792-R (2015-2018).

** José Luis Bellón Aguilera Docent (Prof. Tit.), Departamento de lenguas y literaturas románicas, Universidad Masaryk, Brno (República Checa), 116683@mail.muni.cz godinillo2011@gmail.com. Como hispanista, su campo de estudio incluye la teoría e historia de la literatura española; como helenista, trabaja en el área de investigación del proyecto I+D del que actualmente es miembro: «La recepción de la filosofía grecorromana en la filosofía y las ciencias humanas en Francia y España desde 1980 hasta la actualidad» FFI2014-53792-R (2015-2018). Entre sus publicaciones destacan Anónimo o "Viejo Oligarca": El sistema político de los atenienses (Sevilla: Editorial Doble J, 2017) y Miguel Espinosa, el autor emboscado (Granada, 2012). El presente texto está realizado en el marco del citado proyecto. 


\section{Estudio de caso}

Qué podemos aprender de la democracia ateniense -"the "model case study" (Ober, 2007, 3) - es una pregunta que se lleva planteando desde la antigüedad, pero que hoy, obviamente, ha adquirido una relevancia justificada dada la crisis de representatividad por la que atraviesan la mayor parte de las democracias realmente existentes. Obras eruditas como El proceso de Atenas ${ }^{1}$, entre las muchas posibles -p. ej., de historiadores como L. Canfora o M. Hansen-, ayudan a comprender las formas desiguales como se ha respondido o confrontado la cuestión. La bibliografía al respecto es abundante y creciente ${ }^{2}$. En la historia de la preocupación por la democracia ateniense como fuente de aprendizaje democrático sitúa Josiah Ober $(2007,7)$ un cambio de eje en torno a los años 70 del pasado siglo, cuando se desplazó el foco de estudio de la "Edad de oro" de Pericles a la mejor documentada del siglo IV a. n. e. ${ }^{3}$, la época de Demóstenes. En este giro, sobresale el pionero trabajo del danés Mogens Hansen. Este desplazamiento podría matizarse, por supuesto, pero podemos acompañarle en lo fundamental. La historia de Atenas, a partir del 403 , se consideraba una segunda parte -muy mala- de la grandeza perdida. Se leía como la historia de un fracaso anunciado en la resistencia quijotesca y numantina frente a lo inevitable: el imperio macedonio. La lectura venía de lejos. El artífice de esta visión fue un historiador alemán, representante por antonomasia de los estudios clásicos alemanes, Johann Gustav Droysen (1808-1884), quién había bautizado despectivamente a esta segunda Atenas como "la república de los abogados", por el importante papel jugado en ella del orador y político Demóstenes, "el peor insulto que puede hacerse", según apostillaba -irónico- el historiador conservador Donald Kagan ${ }^{4}$. De esta Atenas tampoco escribió con entusiasmo Francisco Rodríguez Adrados, ni su maestro, Antonio Tovar. Según aquél, carecía de originalidad, no aportó nada nuevo, además de que hubo una "cierta deserción de las tareas públicas" bajo un Estado que garantizaba un mínimo orden con "ayudas, más bien limosnas, a las clases pobres" $(1975,380)$. Claro está que reducir la obra de F. Rodríguez Adrados -que se extiende hasta hoy- a una visión aristocrática, conservadora, de la Atenas democrática, sería simplificar demasiado. No obstante, sí se puede situar su obra (y la de Tovar) en el momento anterior al representado por Hansen.

\section{En el primer giro}

En 1940, un joven Tovar imaginó un programa a largo plazo para la filología española, en el que llama la atención la hibridación de diferentes disciplinas (arqueología, lingüística, filosofía) pero también la mezcla, algo inestable, de ideales del régimen y exigencias

1 Nuestra traducción. Orig.: Roberts, Jennifer T., Athens on Trial, Princeton University Press, 1994.

2 Cabe citar, para España, entre otros, trabajos de Salvador Mas Torres, Laura Sancho Rocher y Domingo Plácido Suárez. La bibliografía fuera de nuestro país es abundantísima: volúmenes colectivos como el dedicado a M. I. Finley (Moses Finley and Politics, 2013), los trabajos de Johann Chapoutot sobre el nazismo (2012), los citados Canfora y Hansen (p. ej., Ideologías de los estudios clásicos (Akal, 1991), y Was Athens a Democracy? (1989), resp.), Paulin Ismard, Miriam Leonard (Athens in Paris, 2005), etc.

3 A.n.e. = "Antes de nuestra era"; se dejará únicamente el año si no se indica otra cosa.

4 “Twilight of the Polis (cont.) and Conclusion", lecture 24, 6-12-2007, en Kagan, 2007 (transcripción). 
científicas: "Procuraremos que España consiga en este orden un nivel decoroso que nos permita presentarnos como dignos sucesores de aquella España de Nebrija y de la Biblia Políglota, que mantuvo con dignidad la filología correspondiente a los siglos de nuestra grandeza"5.

Antonio Tovar Llorente (1911-1985) y Francisco Rodríguez Adrados (nacido en 1922) pueden considerarse los verdaderos fundadores de los estudios clásicos en España, puesto que, a pesar de que la institución de los mismos empezara en los años 30, en plena República, esta historia se truncó y lo que habría salido de ahí solo puede imaginarse. Como ellos mismos señalan, en los años cuarenta, "todo estaba por hacer": no había casi libros, ni traducciones, ni profesores -sobre todo de griego-, pues la situación en el campo del latín era algo más desahogada ${ }^{6}$.

La obra de ambos es enorme: cubre la literatura, filosofía, lingüística e historia griegas, pero también del latín, si bien ambos destacaron como helenistas, y en el caso de F. R. Adrados, como estudioso del indoeuropeo e introductor de los métodos de la lingüística estructural en los estudios clásicos en España. Tovar, a partir de los años sesenta, se iría decantando más por la lingüística comparada.

El campo de la filología clásica recibió un fuerte impulso después de la Guerra Civil, hasta los años sesenta: el latín y el griego jugaban un importante papel en el currículo de la escuela secundaria y los primeros años de comunes en las carreras de filología. A partir de los setenta, sobre todo, comienza un declive institucional que llevó -a través de varias reformas educativas que culminaron en los años noventa del pasado siglo- a su práctica desaparición de la escuela secundaria y a su relegación en las universidades, hasta la actualidad, en que está recluida en sus departamentos.

Es importante recordar esto, ya que la lucha por el mantenimiento del latín y del griego, de los Estudios Clásicos, forma parte sobre todo de la carrera de Francisco Rodríguez Adrados y explica parte de su obra, enfocada en la búsqueda de un público no especialista (y una legitimación institucional e ideológica). Adrados ${ }^{7}$ hizo de esta lucha por la permanencia del latín y del griego en la enseñanza secundaria y universitaria un objetivo vital, en el que empleó una gran energía ${ }^{8}$. Alrededor de una decena de años más joven que Antonio Tovar,

5 Tovar, “Apuntes sobre la filología clásica desde España”, en: Tovar (1941), En el primer giro. Estudios sobre la antigüedad, Madrid, Espasa-Calpe, pp. 127-140, p. 139.

6 Véase el relato en el libro (de 700 páginas) de F. Rodríguez Adrados, en Defendiendo la enseñanza de los clásicos griegos y latinos. Casi unas memorias (1944-2002), Madrid, 2003. Para el período anterior a la guerra civil, el artículo de Francisco García Jurado (2008), "El nacimiento de la filología clásica en España. La facultad de filosofía y letras de Madrid (1932-1936)", en Estudios Clásicos 134, 77-104.

7 A menudo nos referiremos al profesor Francisco Rodríguez Adrados por su segundo apellido, más característico.

8 Todo esto es descrito en su libro, ya citado, Defendiendo..., en el que, por otro lado, el profesor Adrados lanza duros ataques contra la ampliación del acceso a la educación, las reformas educativas y el rebajamiento del nivel, la "egebeización" e "infantilización" de la enseñanza: “...el utopismo pedagógico y sus cantinelas propagandísticas" (2003, 29), "ese igualitarismo o comunismo universalista a bajo nivel en perjuicio de los mejores" (p. 33). La obra abunda en ese tono, en el que puede leerse mucho rencor, destilado contra políticos, pedagogos, psicólogos, contra la especialización, también contra algunos colegas (pp. 310,311) -pero sin nombrar- que no se sumaron a la lucha. Al mismo tiempo, siempre situándose en la defensa de la libertad (no del "utopismo ácrata", p. 105) en los disturbios y malestar universitarios de los 50 y 60 . Dada la lamentable situación de los estudios clásicos en la enseñanza, el rencor es comprensible para una persona como F. R. Adrados, testigo de cómo la introducción de los clásicos grecolatinos en la enseñanza española apenas duró treina o cuarenta años. La obra Defendiendo... 
fue su alumno y discípulo hasta 1944, cuando marchó a Madrid a hacer su doctorado con otro destacado helenista, José Manuel Pabón (1892-1978). Su carrera, centrada en la vida universitaria y cultural, fue brillante.

El caso de Antonio Tovar Llorente (1911-1985) es distinto, pues lo que parece haber marcado su vida es la política, a la que casi se dedica profesionalmente hasta finales de los años cuarenta. Tovar fue en su juventud autor de un panfleto de ideología fascista, $E l$ Imperio de España, aparecido anónimamente en 1936 (y ampliado y reeditado, ya firmado, varias veces), así como de numerosas publicaciones falangistas (Pueblo, Arriba). Formó parte, junto a su amigo el poeta Dionisio Ridruejo (que luchó en la División Azul en el frente ruso), del entorno del filonazi Serrano Súñer, a cargo de la propaganda franquista durante la guerra civil, nada menos que responsable de Radio Nacional. Obviamente, más allá de sus indudables talentos intelectuales y de su enorme capacidad de trabajo, esto aceleró su carrera académica. Formó parte de la delegación española en Hendaya durante la entrevista entre Hitler y Franco, pero como "falangista auténtico" cayó en desgracia ya en los años cuarenta y acabó convirtiéndose en uno de los llamados "falangistas liberales", cuestión esta -espinosa e imposible discutirla aquí- que quizás haya hecho de Tovar un personaje cardinal en las mitologías de la cultura española.

Según Adrados $(2003,70)$, Tovar dejaba la política fuera al entrar en la Facultad. Cómo afinar el análisis para no sobreinterpretar el objeto, dada la especial situación política en España, no resulta tarea fácil. Las vidas de ambos académicos recorren el complicado panorama del franquismo y la transición española, y si el número de sus publicaciones científicas es imponente, no le va a la zaga el volumen de las no científicas; en el caso de Adrados, su labor periodística ha sido y es incansable: ha publicado decenas de artículos de opinión sobre cultura, política, educación, democracia, etc. ¿Cómo se modularon las actividades extramuros de ambos filólogos, sobre todo las de Tovar, con su actividad científica? Como explicaré, la coexistencia en la textura de un trabajo de un inconsciente ideológico y la autonomía científica no está reñida con la riqueza intelectual.

\section{Un mal gobierno que funcionaba bien}

Ellen Meiksins Wood $(1988,1)$ calificaba de tontería -nonsense- la aseveración proclamadamente científica de que el teorema de Pitágoras fue posible porque los griegos tenían esclavos, una elucidación que equiparaba, retorcidamente, la abstracción matemática a la ausencia de trabajo manual. Algo así -añadiríamos- como decir que un arco de herradura es islámico o, en versiones extremas, que para ser geólogo hace falta ser de piedra. La historiadora estadounidense desbrozaba uno de los mitos sobre la democracia ateniense en un trabajo que llevaba su título, "El mito de la masa holgazana": la concepción de que en Atenas la sobreabundancia de esclavos permitía a los atenienses mantener su democracia y su imperio, un mito de transversalidad ideológica mantenido tanto por historiadores liberales, como conservadores, y presente en las "condenas" marxistas de la democracia ateniense ${ }^{9}$. El

es muy útil como relato casi autobiográfico de una trayectoria profesional, pero -en mi opinión- se silencian demasiadas cosas. (Y pretender que sea una "historia y teoría de la educación en España" (p. 421), es excesivo.)

9 Todo esto se relaciona con el tema del trabajo, pero no directamente, de modo que no lo trataré (como se dice, por problemas de espacio). 
cliché de que en Atenas nadie trabajaba se aplicaba profusamente, sin fundamento científico, o contradiciéndolo abiertamente, como el caso de August Boeckh (1785-1867), cuyo pionero trabajo de 1817, The Public Economy of Athens (en la traducción inglesa de 1842) Wood usaba como ejemplo seminal de cómo competencia científica y miopía política, independientemente del ideario, pueden ir de la mano. Resumiendo al máximo: el excelente estudioso alemán, tras un increíble trabajo de compilación de hechos y figuras, defendía lo contrario de lo que se desprendía de las conclusiones de su estudio: el autor afirmaba que en Atenas no trabajaba nadie y que el Estado era una máquina de mantener a una multitud indolentes. Pericles era especialmente condenado, como el arquitecto de un sistema de bienestar social edificado sobre la avaricia y el deseo de poder de las personas más bajas. Como si la investigación para sostenerla refutara la miopía ideológica (uno se siente tentado a utilizar el concepto althusseriano de bévue o lectura errada), Wood mostraba que las conclusiones que se desprendían de una lectura objetiva de los datos aportados rebatían el planteamiento: que las clases "inferiores" de los ciudadanos se veían obligadas a trabajar para sobrevivir.

Si Boeckh condenaba a Pericles, en otra versión del mito, a partir de Jacob Burckhardt y Fustel de Coulanges, "el Estratego" y su época serían convertidos en objetos de culto: el ideal de la acción, de una sociedad agonal -o regida por el principio de la competitividad-, que encontraremos incluso en la reflexión sobre el ser republicano en The Human Condition (1958), de Hannah Arendt, una filósofa de enorme talento, si bien, sobre la democracia ateniense, ceñida a una lectura burckhardtiana.

El relativo desarrollo de la ciencia histórica no justifica un impresionante despliegue de ideología, provenga de donde provenga. En el caso del campo de los estudios clásicos en España, y quizás por su relativa juventud, se percibe una falta de atención a los mecanismos institucionales democráticos atenienses. Por otro lado, se trata de una forma de hacer historia propia de un campo que prioriza el comentario de textos canónicos conservados -literarios y filosóficos- por encima de la investigación de las bases materiales, algo que en España se relaciona con la transformación de la norma de la filosofía tras la guerra civil ${ }^{10}$. Incluso, en ocasiones, se trató de comentarios filosóficos con competencias filológicas. El resultado fue una lectura "moral" de la democracia ateniense, como si se pensase que se trataba de un mal gobierno que funcionaba -o funcionó- bien, gracias al caudillaje de Pericles, al que Adrados considera igualitarista ${ }^{11}$. Sin embargo, un estudio atento a la las lecturas de estos autores del mecanismo más característico de la democracia radical de Atenas -el sorteo- revela que, después de todo, la mirada científica se solapa a la ideológica y la sobrepasa.

\section{El sorteo en Vida de Sócrates, de Antonio Tovar}

Los pasajes de Antonio Tovar sobre el sorteo que he encontrado proceden básicamente de su Vida de Sócrates, un libro de 1947 (segunda edic. 1953, reed. 1966, 1984, etc.), elogiado

10 Véase Moreno Pestaña, J. L., La norma de la filosofía. La configuración del patrón filosófico español tras la Guerra Civil, Madrid, Biblioteca Nueva, 2013.

11 Si Pericles es, para Adrados - quizás también para Tovar u otros helenistas de la época-, un "antifranco" o un trasunto del "caudillo ideal", como Augusto o César lo fueron para los latinistas, se trata de una cuestión complicada a tratar con cuidado en otro trabajo, no aquí. La visión de Pericles en Adrados, en cualquier caso, es progresista. 
por el filósofo Manuel Garrido ${ }^{12}$. Hay otra alusión en una intervención de 1963 (publicada en 1965), escrita para los Coloquios de teoría política de la antigüedad clásica, organizados por la Sociedad Española de Estudios Clásicos y celebrados en Madrid entre el 22 y el 24 de abril de ese año, y de los que hablaré; pero su posición sobre el tema no parece haber variado desde 1947. Que Tovar hable del sorteo en el libro de Sócrates no es sorprendente. Era inevitable, teniendo en cuenta que el célebre filósofo se opuso abiertamente a la selección de cargos políticos e institucionales por medio del sorteo, como han señalado numerosos estudios sobre el filósofo de Alopeke (de los que podríamos citar muchos, pero no es el tema de este artículo) ${ }^{13}$.

Por otro lado, Tovar es autor de la que probablemente fuera la primera edición y traducción española, en una edición bilingüe anotada con un estudio preliminar de unas 30 páginas, de la Constitución de los atenienses de Aristóteles (hoy de autoría cuestionada), publicada por el Instituto de Estudios Políticos en 1948. El I. E. P., creado el 9 de septiembre de 1939 por el gobierno, fue concebido como un brain trust de la Falange Española Tradicionalista, destinado, como laboratorio de ideas, a la formación de los cuadros del partido y al estudio y publicación de clásicos políticos ${ }^{14}$; el organismo acabaría reconvirtiéndose en 1977 (y hasta 1997) en el Centro de Estudios Constitucionales, donde la citada obra se reeditaría bajo nuevo rótulo. Sorprendentemente, en este trabajo no se encuentra ni una observación destacable del sorteo. No aparece en el "Índice de materias", ni hay un comentario de los capítulos 51-54 (cargos sorteables) o 63-69 (los tribunales). Únicamente en una nota aclaratoria se señala que "Todos los que desempeñaban un cargo público tenían a la salida de él que rendir cuentas, y cualquier ciudadano podía acusarles por su conducta durante la magistratura" (cap. 54, p. 181, n. 1). El silencio, o ceguera, parece total. Y sorprende porque Vida de Sócrates, aunque se trata de una obra voluminosa en las que las alusiones al sorteo no llegan a la decena, sí deja clara una posición al respecto, muestra que Tovar conocía el mecanismo ${ }^{15}$. Puede ser que no lo entendiera bien, o que lo leyera como un sinsentido de la democracia radical, o que, incapaz de comprender del todo en los años 40 la democracia representativa (o concibiendo como reales solo formas de esta), la ateniense le pareciera un objeto raro en el museo de la historia. Veámoslo.

\section{La democracia de los salchicheros}

A pesar de que A. Tovar represente, alrededor de los años 60 del siglo XX, a los supuestos "falangistas liberales", sus ideas públicas sobre la democracia no son muy positivas, ni siquiera en los años setenta: en una conocida entrevista de 1973 con Juan Luis Cebrián, el profesor Tovar afirmaría que el pueblo español no estaba preparado para la democracia (entiéndase "representativa").

12 Cita de M. Garrido de Castro Sánchez, Álvaro, "Memoria e Historia de la Filosofía española durante el primer franquismo. Un análisis desde la Sociología de los intelectuales”, Comunicación, Congreso internacional 1936 ¿Un nuevo relato? 80 años, entre historia y memoria, Santiago de Compostela, 20-7-2016. [Inédito. Copia cedida por el autor, 29-6-2016.]

13 Basten Hansen, M., The Trial of Sokrates - from the Athenian Point of View, Copenhagen, The Royal Danish Academy of Sciences and Letters, 1995, o Souto, F., La figura de Sócrates en Jenofonte, [Tesis], UCM, 2003.

14 Véase Payne, S. G., Falange. A History of Spanish Fascism, Stanford University Press, 1961, cap. XV.

15 Las menciones se encuentran en las páginas 63, 80, 282, 322, 326, 338, 342. 
Los posicionamientos políticos de una persona pueden no ajustarse o pegarse a su actividad científica, pero, además, las demandas del campo universitario, en lo que se refiere a las condiciones de posibilidad de expresión política, varían. Puede suceder que la publicación de un trabajo no corresponda a un posicionamiento político e ideológico, que haya un desajuste, porque la temporalidad de los espacios es diferente. Algo así como el jet lag o síndrome de los husos horarios en los viajes de larga distancia. Aunque la posición política personal (pública) de Tovar pudiera desplazarse desde posiciones falangistas hacia otras más liberales o democráticas, su posición científica es otra historia. En su obra Un libro sobre Platón (1956), describe la desilusión del filósofo por la condena de Sócrates y la decadencia moral de Atenas en los siguientes términos: "Platón siempre consideró que con la entrada en la política de los salchicheros y de los curtidores había fallado algo muy importante, y ello por sí explicaba suficientemente la degeneración moral que le asqueaba y mantenía alejado" (1956, 19). Qué fue ese "algo muy importante" que explicaba la "degeneración moral" no se nos explica.

La cuestión aquí no es si colocarle o no al sujeto Tovar la etiqueta de "fascista" o de “elitista" conservador; ojalá fuera tan sencillo. Las modulaciones de los posicionamientos políticos de un individuo pueden variar, o disfrazarse, sin que sea posible saber si lo que se dice públicamente corresponde a lo que se piensa en privado. No creo que sea posible dilucidar la estructura de un "sentido del juego", de un habitus vivo, en tensión entre dos campos de delicada permeabilidad como el político y el universitario. Además, puede que los lenguajes usados en distintos espacios de ambos campos varíen, y que se pudiera hablar de una balcanización del habitus. Quizás la porosidad de las ideas que Tovar tenía de la democracia moderna cuando hablaba o escribía como político difiriera cuando trabajaba sobre la antigua como universitario. No hace falta mencionar qué lenguaje usaba, en distintas fases de su carrera, para el campo político. ¿Cuál es, en definitiva, la relación de estas ideas cuando estudiaba la democracia ateniense? ¿Basta con efectuar un plegado de la posición política y su elitismo sobre el trabajo académico? Tal vez podamos averiguarlo mejor observando si hay desajuste entre los conocimientos de historia de Atenas (es decir, si se conoce el funcionamiento del sorteo) y la ideología de esta persona.

\section{El sorteo, base de la democracia}

En 1963 Tovar regresaba a Madrid desde su exilio voluntario en Illinois. En "Sobre la teoría política de Sócrates y Platón", la ponencia presentada en los Coloquios de 1963 (ya citados), se describe la admiración por Esparta de Sócrates y su rechazo de "las bases mismas de la democracia (la designación de cargos por sorteo, los subsidios que permiten a los ciudadanos pobres intervenir activamente en la política, la conversión del Estado en instrumento del imperialismo económico) tal como había quedado conformada con Pericles" (Tovar, 1965, 72). De este texto se desprende que el vallisoletano no ignora cuáles fueron "las bases mismas de la democracia" (en el paréntesis que las sigue). Otra cosa es que no pueda ver el potencial de estos mecanismos.

En 1947 -Vida de Sócrates - la cuestión del sorteo está pegada a la reflexión sobre el destino del filósofo. La Atenas de Tovar es una pólis democrática en la que predominan "las gentes más arraigadas, más dependientes de la tradición, más respetuosas con las fórmulas 
heredadas. A la igualdad democrática, la isonomía, se ha llegado por el desgaste de una sociedad vieja" (p. 57). Sócrates un ser arraigado, que mira las instituciones atenienses con respeto, incluso admiración, pero que repudia la democracia radical. El problema de Atenas es el triunfo de "la ilustración" (59), y el desapego de la "plebe" de la ciudad, que racionaliza las instituciones heredadas. Sócrates se opone a esto y deriva hacia el individualismo, del cual surgirá una nueva ética, anunciadora de Platón y, a largo plazo, del cristianismo ${ }^{16}$.

Tovar dibuja una Atenas democrática aquejada de un "feroz predominio de la envidia" (71), en la que el salario por participar en la vida pública "se convierte en medio de vida para los pobres y los holgazanes, que así se sienten dueños de vidas y haciendas de los demás" (íd.). Esto recuerda, obviamente, "el mito de la masa desocupada" (u holgazana) de Ellen Wood. La edad de Pericles, durante la que, paradójicamente, suceden las reformas más radicales de la democracia, según Tovar, es contemplada como el último momento de gloria antes de la inevitable decadencia. El hijo de Sofronisco, del demo de Alopeke, ha pasado en Salamanca a convertirse en un ente más imaginario -o literario- que real, mezcla de raciovitalismo y arraigo a la tierra. Un rebelde religioso y patriótico que intenta contener la decadencia provocada por el racionalismo y la modernización. Las palabras clave son tierra, tradición, religión e irracionalismo: mitemas falangistas, y Tovar, en 1947, todavía lo era, y "auténtico".

Hay un pasaje (p. 63) que nos recuerda que el sorteo es el fundamento de la democracia, si bien la sofística -se nos narra- está poniéndola en peligro: "Las ideas nuevas: la filosofía jónica, la sofistica, ponen en peligro la santidad de las viejas leyes y costumbres, la democracia fundada en gran parte en el sorteo de cargos, la eunomía o paz basada en el respeto a las leyes, tal como Solón la había cantado hacía dos siglos" (Tovar, 1984, 63). Atenas se embarca en aventuras demasiado grandes para sus fuerzas materiales, y Sócrates, ciudadano a la antigua, no ve bien el imperialismo de Pericles, ni varios de los "dogmas democráticos", entre ellos "la designación para los cargos por sorteo y el derroche de dinero que suponían los sueldos e indemnizaciones" (p. 80); el filósofo se opone a la racionalización de las instituciones veneradas por la plebe y a las reformas radicales. Se vuelve individualista.

Durante el proceso de las Arginusas (406/5 a.n.e.), se ve obligado a desempeñar un cargo en el Consejo de los Quinientos, "sin duda obligado por el sorteo" (p. 322), lo cual es probable, pero no se dan fuentes. Sócrates no discrepaba, sin embargo, no se apartó de las instituciones heredadas, pero echó de menos los felices tiempos de juventud, cuando había una constitución sólida (326). No era un conspirador, aunque fuera acusado de enseñar a jóvenes a no obedecer las leyes (342). Él no lo pretendía en realidad, sino que era una de las paradójicas consecuencias que había tenido su enseñanza, su "crítica racional de ciertas instituciones heredadas, como el sorteo de cargos públicos" (342). Sus amigos y discípulos -imbuidos del racionalismo sofístico- carecían del respeto a la ciudad y las leyes y, como Critias y Alcibíades, habían resultado violentos y facciosos (o bien, matiza, "partidarios de la acción directa", íd.).

No deja de haber contradicciones en la argumentación de Tovar. Por un lado, piensa (p. 338) que los tribunales atenienses, mediante el sorteo, dejaban la justicia en manos de los dioses, en la divina suerte (que decidan ellos). Puesto que Sócrates era religioso y tradicional, "sentía verdaderamente viva esa sanción moral que la ciudad prestaba a las leyes", aunque

16 Véase Tovar, A., "Sócrates y el cristianismo", en Alférez, año I, núm. 3, 1947, p. 3. 
fuera una injusticia. Si esto es así, ¿cómo se compaginaba, según la argumentación de Tovar, el apego a la ciudad, con su crítica del sorteo? En primer lugar, el sorteo era el método de selección de los jueces, no de sus decisiones. En segundo lugar, quizás Tovar hace, inadvertidamente, una lectura del dogma religioso que no concuerda con la visión griega de la religión: el filólogo español lo lee en clave cristiana: el dogma no se cuestiona; no ve -en este caso- que los atenienses discutían los mitos y la religión dentro de unas normas no escritas que excluían la blasfemia, la mofa y la negación de los dioses. En definitiva, Tovar ve raíces religiosas en el sorteo, y se apega a ello para no hacer del de Alopeke un racionalista radical, lo que cuadra con la visión que ofrece de él como un conservador rebelde, un "conservador revolucionario"17. Porque, además, según Hansen (1999, 50), a pesar de los -posibles- orígenes en la religión griega, en el siglo V el sorteo es reinterpretado como el procedimiento democrático por excelencia para mantener la igualdad política.

¿Puede concluirse algo? El sorteo y el salario son considerados por el vallisoletano como la "base de la democracia" (ateniense), aunque, al mismo tiempo, su retrato le sugiere el lado oscuro de la democracia, y una de las causas de su decadencia. Podemos leer esto al revés: Tovar comprende el potencial del sorteo para una mayor participación democrática, pero lo rechaza, profundamente. El rigor histórico, filológico, le obliga a tenerlo en cuenta, y se justifica por motivos religiosos, esto es, que pertenece a la galería de un museo de antigüedades históricas, sobrepasado por el espíritu de los tiempos. Con todo, el problema no era invisible. ¿Cómo es tratado por su discípulo y colega Francisco Rodríguez Adrados?

\section{El sorteo en Francisco Rodríguez Adrados}

Según Adrados, Sócrates aspiraba a una "profesionalización de la política desde puntos morales y técnicos, diríamos; la política debía ser un "arte"” $(1997,82)^{18}$. Escaso es lo escrito en Democracia y literatura sobre el sorteo y sobre las instituciones (y poco sobre las culturales), salvo reenviar al lector -en varias ocasiones- a una de las primeras obras importantes del autor, Ilustración y política en la Grecia clásica ${ }^{19}$. Publicada en 1966 por Revista de Occidente, el mismo año y editorial que una de las reediciones de la Vida de Sócrates de Antonio Tovar, Ilustración y política es situada y citada por el profesor Rodríguez Adrados junto a la versión abreviada de 1975, titulada La democracia ateniense, en la que nos centraremos ${ }^{20}$.

17 Véase el texto de P. Bourdieu sobre Heidegger y su entorno cultural, en The Political Ontology of Martin Heidegger, Cambridge, Polity Press, 1991.

18 En Democracia y literatura en la Atenas clásica (1997) -obra citada por J. Ober- y en un texto redactado para este libro, pero eco de otros trabajos anteriores sobre Platón y Sócrates. En 1997, además de la obra divulgativa del mismo Adrados, Historia de la democracia. De Solón a nuestros días, aparecieron en España La sociedad ateniense. La evolución social en Atenas durante la guerra del Peloponeso, de Domingo Plácido y Un proyecto democrático: la política en la Atenas del siglo V de Laura Sancho Rocher.

19 El profesor Adrados menciona también en una ocasión su "Teoría política de la democracia ateniense", ponencia de los Coloquios de teoría política de la antigüedad clásica -ya citados, y a los que volveremos-, donde no se menciona ni discute el sorteo, y que parece un texto que prefigura Ilustración y política. Otras obras más recientes reproducen argumentos: así Historia de la democracia (citada en la nota anterior) y Nueva historia de la democracia. De Solón a nuestros días (2011), reseñada por Bellón, J. L. en Sociología histórica 2/2013: 453-463.

20 Adrados dirigió el departamento de Griego de la UNED entre 1972-1976, lo que quizás explica, en parte, la reedición de 1975. La reducción de Ilustración y política consistió en aligerar el volumen: descartar notas, ejemplos de textos, varios pasajes y un capítulo entero ("La Ilustración, el Conocimiento del Hombre y la Cien- 
El sorteo es mencionado en La democracia ateniense algo más de una docena de ocasiones ${ }^{21}$. Se apunta su origen y se discute su generalización como procedimiento democrático, a partir, primero, de las reformas de Clístenes del 508/7, las del 487 con, quizás, Temístocles (cf. Hansen, 1999, 34 y ss.) y la instauración del Consejo de los Quinientos, del que -señala el filólogo salmantino- no sabemos la fecha de creación ni si era sorteado (p. 94), igual que la "oscura reforma del 501/500". El autor se centra en la radicalización progresiva de las reformas: el "golpe decisivo" al arcontado "cuando en el 487/86 deja de ser cubierto por elección y se provee mediante klêrôsis ek prokrítôn, es decir, mediante sorteo entre candidatos previamente escogidos entre las dos primeras clases (las tres primeras desde el $457 / 56$, con sorteo puro y simple)", explicando que "la estrategia" (los generales) no podría otorgarse por sorteo, haciendo de esta magistratura la primera de Atenas (pp. 111-112; 232)22.

Rodríguez Adrados hace de Pericles, después de Clístenes -obviamente-, el principal reformista radical de la democracia. Tras el desplazamiento del equilibrio entre aristocracia y pueblo, a Pericles se debe la introducción de la graphê paranómôn, o proceso por ilegalidad, como medida preventiva ante "futuras revoluciones", "una corrección que sigue a la consistente en atribuir el arcontado por sorteo" (113-114). El alcmeónida, partidario ferviente del sistema democrático y promotor de reformas (231-233), participó en la revolución de Efialtes -“el Robespierre griego" (113, n. 19)- del 462, el derribo del Areópago, y fue llamado por el poeta cómico Cratino "hijo de stásis, Revolución” (p. 233). Durante el tiempo de su carrera política se impuso la elección por sorteo de la mayoría de los cargos, accesibles a toda la población, salvo los que exigían competencias específicas, como, p. ej., cargos financieros (233).

Es posible que Adrados exagere el papel del estratego Pericles, si bien es cierto que durante su carrera política, de liderazgo incuestionado pero no incontestado, tienen lugar algunas de las reformas más radicales, incluidas la introducción del salario para la participación política y la ley de ciudadanía (cf. Hansen, 1999, 38), asunto este en que Adrados no abunda. Este insiste más en la extracción económica, de clase, de los beneficiados por el sorteo, a propósito de los heliastas y la Asamblea (p. 238), pero también concede que cualquier ciudadano ateniense adquiría "una notable experiencia política, militar y administrativa" (238) en su participación, y es que la democracia bajo Pericles - añade -, eleva el nivel material y espiritual ("y trabajo", íd. 238). Estos veredictos contrastan con las continuas alusiones al desastre moral y social provocado por el intento de igualdad política y económica, tras la muerte del caudillo alcmeónida: el tema del fracaso de la democracia, como se verá más abajo.

A partir del óbito de Pericles hasta los capítulos sobre Sócrates y la filosofía de Platón, La democracia ateniense no dará más lugar al sorteo, y cuando se otorgue será para mani-

cia”), además de la remodelación del capítulo 4 ("Pericles y la democracia de su época”) y el Epílogo ("Historia griega e historia del mundo"); este último, poco corregido en 1975, es interesante, entre otras cosas, por basarse en las ideas de un historiador vinculado al nacional-socialismo, el austríaco Fritz Schachermeyr (1895-1987), de acuerdo con el artículo de Pesditschek, M., "Die Karriere des Althistorikers Fritz Schachermeyr im Dritten Reich und in der Zweiten Republik", en Pesditschek, 2007, 41-71.

21 Págs. 94, 111-112, 113-114, 231, 232, 233, 238, 391, 393, 405, 425.

22 La noticia procede de Aristóteles, Ath. Pol. 22.5 (de Hansen, 1999, 36, n. 124), que consultamos en A. Tovar (1948). La expresión klêrôsis ek prokrítôn procede probablemente de Arist. Ath. Pol. 8.1, aunque se habla de las reformas de Solón. 
festar las críticas de los filósofos (p. 391)23. La de Sócrates -se narra- no es una actitud anti-democrática, sino oposición a la demagogia y desconfianza del sistema del sorteo para cargos públicos y del acceso a la política de "aficionados sin preparación" (393), ocupando un espacio importante del gobierno y el Estado en detrimento de las élites y de los expertos. Aunque se reconoce la deuda con Vida de Sócrates (p. 388), el parecido es limitado: no se hace del viejo filósofo un partidario ni de la aristocracia ni de la democracia tradicional, sino un precursor de Platón. El de Alopeke es un filósofo independiente que "choca" tanto con los excesos de la democracia, como con sus formas más moderadas (la restaurada del 403). Fundador de una ciencia política cuyo objetivo es el perfeccionamiento moral del pueblo, para él el sistema de sorteo es "absurdo" (405), pues la política es un "arte" especializado o technê practicada por la casta de los filósofos (cf. Adrados, 1997, 82, referencia con la que inicié este apartado). Aparte de esto, no hay apenas más alusiones al sorteo, aparte de una referencia a la eugenesia de las platónicas Leyes ${ }^{24}$.

El profesor Adrados se aleja de Vida de Sócrates de manera general, no en lo sustancial. No hace del maestro de Platón un pensador pre-cristiano, aunque parece sugerirse, al señalar que ha destruido la religión y la política griegas y que ha sentado los fundamentos de una religión y política universales. Sí lo convierte en un pre-platónico, aunque no se problematiza el hecho de que Sócrates lo sea debido a la fuente principal usada para su argumentación, Platón, ya que el de Jenofonte parece deshojado de Tovar. Afirma el autor que hay larvada en el de Alopeke "una política moralista y totalitaria" (406) ${ }^{25}$. La crítica a la epistemocracia platónica, probablemente enmascara -como en su maestro, claramente- un sesgo anticomunista del autor, más que la línea de Karl Popper, cuya obra The Open Society and Its Enemies, de 1945, es tildada de "exagerada" (p. 410).

En Adrados puede leerse entre líneas una justificación razonada de la posición socrática contra el sorteo. "Razonada" relativamente, pues se la considera desde un prejuicio elitista contra la carencia de capital cultural, la desprofesionalización de la política, la falta de competencias o la debilidad moral ${ }^{26}$. El sentido común o los fantasmas ideológicos se imponen a un texto que, por efecto del estudio, reconocía que la clave de la democracia ateniense era la participación y que el paso por lo público dotaba a los ciudadanos de "una notable experiencia política, militar y administrativa" (238) -como apunté-. Hay en Adrados una visión progresista del "primer ciudadano" o caudillo Pericles -insistimos-, y una crítica de las insuficiencias feministas y sociales (la esclavitud, los extranjeros) de la democracia ateniense (véase p. $315,351,443$ ). Pero sucede que no se puede cruzar la barrera ideológica de la resistencia a la democracia directa, alzada por el sistema de sorteo. Una comparación entre los trabajos de Tovar y Adrados arroja conclusiones interesantes.

23 La democracia ateniense dedica a Sócrates y Platón, respectivamente, los capítulos 1 y 2 (total unas 45 páginas) de la tercera parte. El profesor F. R. Adrados había publicado además sobre Sócrates en 1956 un trabajo que luego reeditaría, traducido, en 1992, donde las dos únicas alusiones al sorteo no expresan nada diferente.

24 "Para que del acoplamiento de los guardianes nazca una raza fuerte, en el sorteo con arreglo al cual se efectúa se harán determinadas mixtificaciones" (425).

25 Para Tovar, "Es una utopía para la filosofía, no como el comunismo o para hacer felices a las personas", en Tovar, A., "El verdadero fin de la utopía platónica", en Estudios clásicos, 1/2, 1951, pp. 73-80.

26 Véase al respecto el trabajo de reactualización del sorteo de O. Dowlen, "Marco para la consolidación y defensa de una democracia ciudadana” (especialmente pp. 2, 5, 17), traducido por J. L. Bellón, en Oliver Dowlen y Jorge costa Delgado, El sorteo en política: cómo pensarlo y cómo ponerlo en práctica, Sevilla, Editorial Doble J, 2016. 


\section{8. ¿Una democracia precaria?}

Las oscilaciones de Tovar y Adrados son el resultado de la imposibilidad de negar la evidencia histórica que se desprende de sus textos, mezclada a ciertos prejuicios ideológicos y del habitus universitario, en parte también el de clase. Obviamente, lo que digo se refiere a los textos, no a los individuos reales. Podemos resumir en tres puntos los que me parecen que son los problemas centrales de su recuperación de la democracia ateniense, para luego concluir apuntando lo logrado, en un breve epílogo.

En primer lugar, el método elegido para tratar la democracia ateniense -el comentario interno de los textos canónicos literarios y filosóficos- es insuficiente. Responde a la configuración del patrón filosófico en España tras la guerra civil, a una forma de trabajar que consiste básicamente en el comentario sistemático, "escolástico", de textos canónicos (véase Moreno Pestaña, 2013). El apego a la letra escrita y a la glosa es más cuestionable en Adrados, aunque se equilibra con el uso de historiadores, si bien se echan de menos obras como las de M. I. Finley (1912-1986), activo desde los años cincuenta y de la misma generación biológica que Tovar. Cabe preguntarse por qué razón no hubo una actualización en 1975 de Ilustración y política; en Tovar resulta incomprensible cómo pudo reeditar una obra apenas modificada desde las ediciones de 1947 y 1953. Paradójicamente, allí donde Tovar es menos ideológico, en el rigor histórico, Adrados no lo es, lo que hace de la escritura del vallisoletano menos escolástica y más creativa (quizás por su procedencia cercana a un campo cultural más “orteguiano") que la de su discípulo, más preocupado por demostrar su conocimiento del canon y de bucear en el mismo.

En segundo lugar, tanto Adrados como su maestro Tovar, al estilo de lo que el sociólogo estadounidense Charles Wright Mills, en una obra contemporánea, The Sociological Imagination -de 1959- llamó "Grand Theories", comparten mitemas ideológicos, al mismo tiempo y alternativamente, con Boeckh y Burckhardt, con Grote y Mitford: que el "gran" siglo de Pericles fue un fracaso porque el bienestar económico no podía mantenerse; que fue un "experimento" (Adrados, 1975, 97, 267, p. ej.) que acabó desintegrándose casi por implosión interna, a partir de la muerte de Pericles hasta el principio del fin desde el 403. Se admira la vitalidad y energía de la democracia radical-imperial, pero se acaba por condenarla, encontrándole causas internas que a menudo son trenzadas a la "naturaleza humana", descubierta por los griegos (cf. p. ej., p. 172 y ss.). La democracia, para Adrados, fracasó en el intento de extender a toda la población el poder y el standard cultural y social de los menos $(1975,442)$; Pericles creyó poder conciliar autoridad y libertad, pero a su muerte sobrevino la guerra civil. En ello influyó que Atenas era una ciudad-estado, pues no se conocía el Estado nacional. Todo ello fracasó, pero no en vano: los griegos -reflexiona el filólogo salmantino- nos mostraron un camino que no pudieron culminar: la empresa democrática es difícil, señaló las metas entonces imposibles de la liberación de la mujer y del esclavo, del extranjero, pero históricamente no pudo ser, de la misma forma que "la igualación de pueblo y aristocracia chocaba con dificultades económicas evidentes y sólo pudo ayudarse algo a la situación mediante la explotación del imperio ateniense, es decir, mediante una escisión de conciencia que propugnaba el humanitarismo sólo para el interior" (442-443). El fracaso es debido, básicamente, a los elementos disgregadores y subversivos procedentes de las clases populares, guiados por el egoísmo propio de la naturaleza humana. La muerte del caudillo conduciría a la catástrofe: las clases populares habían ganado un excesivo poder, y "estas clases eran en buena parte incultas y atrasadas y llegaron llenas 
de violencia y pasión; lejos de contentarse con ejercer el control del Estado para evitar los abusos de autoridad, hicieron del voto un arma para sus propios intereses, tanto los legítimos como aquellos que estaban en contradicción con los de la ciudad o el resto de la población: de la tiranía de la minoría se pasó a la de la mayoría" (443-444). Acabaron incluso matando a Sócrates. La lectura no difiere de la teoría del "dêmos-tirano" que encontramos en toda la propaganda antidemocrática desde sus inicios, de Jenofonte, del Viejo Oligarca y Platón, e incluso recuerda a planteamientos similares en La España invertebrada o La rebelión de las masas. De hecho, la continua insistencia de Adrados en la "conciliación democrática" lograda, previa a la decadencia, revelan más sobre las ideas del autor que sobre la historia de Atenas, o bien una visión moderada de la democracia. Nótese que no desarrolla una discusión profunda del uso del golpe y del asesinato políticos por parte de los oligarcas (véanse pp. 332, 359), quizás -concedamos- porque se está en 1966 o 1975 (tiempos del “búnker”) aunque, por otro lado, apenas se habla de la amnistía del 403 y no se menciona a Trasíbulo ni a Anito, símbolos de la bondad del pueblo democrático para John Stuart Mill27. El dilema que vivieron los griegos, para Adrados (445-446), es el nuestro: el riesgo de la libertad, el riesgo de la planificación; demasiada libertad, demasiado igualitarismo. Y no se trata sólo de un prejuicio antidemocrático, sino también del tradicional relato de que todo fue mal porque después de Pericles no hubo líderes de su talla. A pesar del rigor histórico que hemos señalado en ambos, aquí se hace necesario señalar un anacronismo. En Atenas -según explicaba Finley en un ya clásico ensayo "Los demagogos atenienses"-28 no había "líderes" en el sentido moderno, miembros de una facción o partido, sino dirigentes-oradores individuales, en general procedentes de clases aristocráticas o adineradas (esto es, que podían costearse una buena educación retórica) que se dirigían al pueblo y podían pagar muy caro -ostracismo, proceso o incluso condena a muerte- las consecuencias de un mal consejo o de una propuesta errada.

En tercer lugar, cuando los dos universitarios se centran, como se ha dicho, en las fallas internas de la democracia, hay una especie de teleología moral o ideológica que no tiene en cuenta, precisamente, que la historia no es un a priori porque la miremos desde el futuro. Los atenienses no sabían que las cosas iban a terminar como terminaron. Su democracia cayó tras la invasión macedonia y el hecho de que la democracia directa ateniense sea una "anomalía histórica" se debe a esta derrota. El historiador estadounidense -conservador- Donald Kagan lo ve de otra forma. En la lección 24 de sus cursos del 2007 sobre el tema -ya citada- explicaba convencido que la batalla de Queronea (338 a.n.e.) no fue de ninguna manera un paseo militar: incluso sin los espartanos podría haber sido ganada por la coalición griega liderada por Atenas y Tebas, como otra Maratón. Demóstenes puede resultar ridículo a historiadores alemanes como el nacionalista Droysen, porque perdieron y no quisieron ver que Alejandro era "inevitable" (tenía que serlo, como Bismarck). "Hombres como Churchill y Demóstenes" -proclama D. Kagan al final de su conferencia- "saben que aquellos que aman la libertad deben luchar por ella, incluso en desventaja, incluso sin apoyos suficientes, incluso cuando la victoria parece imposible; a pesar de su desenlace, creo que la resistencia de Atenas y sus aliados griegos en Queronea puede haber sido, en palabras que Churchill usó en otro contexto, "su mejor hora", "their finest hour".

27 Debo (y agradezco) la referencia a Mill a J. L. Moreno Pestaña.

28 En Finley, M. I., Vieja y nueva democracia, Barcelona, Ariel, 1981, pp. 121-163, si bien procede de una obra anterior de 1974 y se trata de un texto revisado de 1961 . Véanse pp. 148 y ss. 


\section{Epílogo. Coloquios madrileños. Defendiendo los estudios clásicos}

Uno de los textos-madre de Ilustración y política fue "La teoría política de la democracia ateniense", ponencia en los Coloquios de teoría política de la antigüedad clásica, de la S.E.E.C. entre el 22 y el 24 de abril de 1963. Los coloquios consistieron en la presentación de una ponencia, a la que siguió un coloquio-debate y todos fueron estenografiados, transcritos y revisados por sus autores para su publicación ${ }^{29}$. Además de la ponencia de F. R. Adrados, Antonio Tovar y Alvaro D’Ors participaron con sendos trabajos sobre Platón y Sócrates y "El no estatismo del Imperio Romano". Entre los participantes, se contaba lo mejor de la filología clásica española: Fernández Galiano, Lasso de la Vega y Luis Gil, Hernández Vista, Calonge, Lledó, Díaz Tejera, Dolc, García Calvo, Ruipérez, Ruiz de Elvira. "Lledó" quizás sea el filósofo Emilio Lledó, que acababa de regresar de Alemania y daba clases en un instituto de Valladolid. La intersección de campos es visible en la presencia activa Álvaro d'Ors (1915-2004), de la Universidad de Navarra desde 1961/2 (antes catedrático de Derecho Romano en Granada), miembro del Opus Dei desde 1949, e hijo de Eugenio d'Ors, el pensador de la -para algunos- "Atenas del Arga", en las riberas del río pamplonés del mismo nombre. Se discutió de democracia griega (laica y religiosa), república romana, monarquía, Imperium, Estado, caudillaje, filosofía (Sócrates, Platón, los sofistas, Carl Schmitt, Maquiavelo...), y otros temas de historia de Grecia y filosofía política organizados en torno a la idea de democracia. Leídas las ponencias y coloquios, se percibe que la terminología del profesor Adrados está presente en los ponentes, con la salvedad de Álvaro d'Ors, quien intenta defender el carácter ateórico (no anti-teórico) de "los romanos" y la "vigencia de una concepción personalista" en la tradición occidental, procedente de Roma, la cual -y citaba a Carl Schmitt- no tenía Estado.

La ponencia de Adrados hablaba de una "democracia religiosa", teorizada por Esquilo, y una "democracia laica”, que vendrá después. En cierto momento usó un lenguaje que, en 1963, debía sonar fuerte en ese espacio social: Adrados habla de una tendencia a la igualdad arruinada por la guerra del Peloponeso y por los conflictos internos, pero de unos "valores expansivos", "la libertad, la humanidad, la igualdad", que contradecían las limitaciones históricas (ciudad-estado, esclavitud, androcentrismo) y tendencias del ser humano; en cualquier caso, dijo, "de lo que no cabe duda es de que la peripecia griega es ejemplar. Y de que toda una fase del pensamiento político griego, la fase liberal y democrática, debe ser sacada del olvido en que en gran parte yace" (p. 28). Con un final así, la discusión fue servida en bandeja, básicamente con las adversativas de d'Ors, el apoyo de Lledó (que dará la nota al día siguiente en la ponencia de Tovar citando a Grote y Popper) y el relato antidemocrático de Gil (56-57). Sin embargo, la actitud general en los participantes es que la democracia ateniense no funcionaba, que fracasó. En una intervención de tres páginas que su autor corrigió y envió íntegra a la redacción de la revista, el gran latinista Antonio Ruiz de Elvira Prieto (1923-2008), verbalizaba su disgusto con una metáfora cromática: el azar ("esa týchê") frustra toda utopía democrática, "hace absolutamente imposible todo democratismo de color de rosa"; así, el "pesimismo" de Eurípides -argumentaba- no es

29 Véase Estudios clásicos, 44, 1965; los textos están disponibles en internet. Online <http://interclassica.um.es/index. php/interclassica/investigacion/hemeroteca/e/estudios_clasicos/numero_44_1965> [Consultado 15-3-2016]. 
sino la "expresión del fracaso de los ideales de la democracia", consecuencia lógica "de las vías de agua que quedaban abiertas en Esquilo" (Rodríguez Adrados, 1965, 60). Los valores de la libertad -finalizaba- "no son patrimonio, ni muchísimo menos, de la democracia. [...] No es la política de Atenas, ni ninguna otra, lo que hace ejemplar la peripecia griega". Adrados contestará que él no ha venido a cantar las alabanzas de la democracia ateniense, pero tampoco lo contrario: contrapondrá el "lirismo" y "tinte rosado" de la primera sofística ("se ha hablado mucho de política color de rosa"), su fe en la igualdad y el logos, a "la tesis contraria de que hay una raza o generación de hombres superiores como los que quiere formar Platón" (63-64). Y finaliza de forma elegíaca, en la fe y esperanza de que "a pesar de todas las dificultades, los problemas humanos logren, por lo menos, acercarse a una cierta armonía, a un cierto acuerdo". "Conciliación democrática" era la palabra con que Adrados, en Ilustración y política, definía como el momento más perfecto de la democracia ateniense, tras la derrota de los persas, durante la época de las tragedias de Esquilo. Al par que la mirada científica -no así la política- viera el mecanismo del sorteo, es esta recuperación del debate del "caso modélico" democrático lo que podemos considerar uno de los logros fundamentales de Francisco Rodríguez Adrados. La versión revisada de La democracia ateniense apareció en un escenario conveniente. Dos años después, en 1977, tenían lugar en España los llamados "Pactos de la Moncloa".

\section{Referencias}

Bourdieu, P. (1991): The Political Ontology of Martin Heidegger, Cambridge, Polity Press. Finley, M. I. (1980): "Los demagogos atenienses", en: Finley (1980), Vieja y nueva democracia, Barcelona, Ariel, 121-163.

Hansen, M. H. (1999): “The Athenian Constitution down to 403 BC: A Historical Sketch", en: Hansen, M. H. (1999), The Athenian Democracy in the Age of Demosthenes. Structure, Principles, and Ideology, Norman, University of Oklahoma Press [Transl. by J. A. Crook.], pp. 27-54.

Hansen, M. H. (1995): The Trial of Sokrates - from the Athenian Point of View, Copenhagen, The Royal Danish Academy of Sciences and Letters, Historisk-filosofiske Meddelelser, 71.

Kagan, D. (2007): Introduction to Ancient Greek History, Yale Online Course < http://oyc. yale.edu/classics/clcv-205\#overview > [Consultado 2-09-2014].

Moreno Pestaña, J. L. (2013): La norma de la filosofía . La configuración del patrón filosófico español tras la Guerra Civil, Madrid, Biblioteca Nueva.

Ober, J. (2007): "What the Ancient Greeks Can Tell Us About Democracy", Princeton/ Stanford Working Papers in Classics, publ. Annual Reviews in Political Science 11:6791. <http://www.princeton.edu/ pswpc/pdfs/ober/090703.pdf> [Consultado 18-08-2015]

Payne, S. G. (1961): Falange. A History of Spanish Fascism, Stanford, Stanford University Press.

Pesditschek, M. (2007): "Die Karriere des Althistorikers Fritz Schachermeyr im Dritten Reich und in der Zweiten Republik", en: Mensch - Wissenschaft - Magie. Mitteilungen der Österreichischen Gesellschaft für Wissenschaftsgeschichte, 25, pp. 41-71.

Rodríguez Adrados, F. (2011): Nueva historia de la democracia, EBook [epub, Kindle], Newcomlab. [Ed. en papel: Barcelona, Ariel, 2011.] 
Rodríguez Adrados, F. (2003): Defendiendo la enseñanza de los clásicos griegos y latinos. Casi unas memorias (1944-2002), Madrid, Ediciones Clásicas - Fundación Lexis pro Diccionario Griego-Español.

Rodríguez Adrados, F. (1997): Democracia y literatura en la Atenas clásica, Madrid, Alianza Editorial.

Rodríguez Adrados, F. (1975²): La democracia ateniense, Madrid, Alianza Editorial. [Quinta reimpresión, 1993; primera edic. 1966, Ediciones de la Revista de Occidente, como Ilustración y política en la Grecia clásica.]

Rodríguez Adrados, F. (1965): "La teoría política de la democracia ateniense [Ponencia y coloquio]”, Estudios clásicos, 9, 44, 1965, pp. 11-64. En línea (Hemeroteca InterClassica) <http://interclassica.um.es/index.php/interclassica/investigacion/hemeroteca/e/ estudios_clasicos/numero_44_1965/coloquio_sobre_la_teoria_politica_de_la_democracia_ateniense_ponencia> [Consultado 30-5-2013]

Rodríguez Adrados, F. (1956): “Tradition et raison dans la pensée de Socrate”, Bulletin de l'Association Guillaume Budé 4, 1956, pp. 27-40. [Traducido en: Rodríguez Adrados, F. (1992), Palabras e ideas, Madrid, Ediciones Clásicas, pp. 233-249.]

Souto Delibes, F. (2003): La figura de Sócrates en Jenofonte, [Tesis], Universidad Complutense de Madrid, Facultad de Filología, leída el 15-06-2000, Dir. Alberto Bernabé. URL Oficial <http://eprints.ucm.es/tesis/19972000/H/3/H3074101.pdf> [Consultado 2-9-2015]

Tolbert Roberts, J. (1994): Athens on Trial, Princeton, Princeton University Press.

Tovar, A. (1984): Vida de Sócrates, Madrid, Alianza Editorial. [Revista de Occidente, 19471.] Tovar, A. (1965): “Coloquio sobre la teoría política de Sócrates y Platón [Ponencia y Discusión]”, Estudios clásicos, 9, 44, 1965, pp. 77-103. En línea (Hemeroteca InterClassica) < http://interclassica.um.es/investigacion/hemeroteca/e/estudios_clasicos/ numero_44_1965/coloquio_sobre_la_teoria_politica_de_socrates_y_platon_ponencia > [Consultado 21-12-2015]

Tovar, A. (1956): Un libro sobre Platón, Madrid, Espasa Calpe., Colecc. Austral.

Tovar, A. (1951): "El verdadero fin de la utopía platónica", Estudios clásicos, tomo 1, n. 2, pp. 73-80.

[Tovar] Aristóteles (1948): La constitución de Atenas, Ed. Trad. Notas y estudio preliminar, de Antonio Tovar, Madrid, Instituto de Estudios Políticos.

Tovar, A. (1947): "Sócrates y el cristianismo", Alférez, año I, núm. 3, p. 3. Online <http:// www.filosofia.org/hem/194/alf/ez0303.htm> [Consultado 24-5-2016]

Tovar, A. (1941): “Apuntes sobre la filología clásica desde España”, en: Tovar, A. (1941), En el primer giro. Estudios sobre la antigüedad, Madrid, Espasa-Calpe, pp. 127-140.

Wood, E. M. (1988): Peasant-Citizen and Slave. The Foundations of Athenian Democracy, Londres - Nueva York, Verso. 